\title{
EDUCACIÓN A DISTANCIA: NOTAS SOBRE UNA EXPERIENCIA RECIENTE
}

"Personalmente, y por el momento, estoy determinado a ofrecer cierta resistencia (bajo la forma silenciosa de la inercia) al furor por reemplazar, cada uno de los átomos de interacción en presencia real que van quedando, por esas deplorablemente higiénicas pantallas de

computador. [...] era talvez necesario recorrer un desarrollo así complicado del concepto de "presencia" con el fin de darse cuenta de que nuestra propia profesión de enseñar, muy específicamente y de modo no completamente pensado, siempre ha tenido que ver con la presencia real. Pero no hay garantía de que esto siga siendo así. El futuro de la presencia requiere de nuestro presente compromiso".

Hans Ulrich Gumbrecht

"¿Dónde se encuentra hoy el lugar comunitario y el vínculo social de un «campus» en la época ciberespacial del ordenador, del teletrabajo y de la world wide web?"

Derrida

\section{Posiciones}

Ante la amable invitación para participar en esta revista, no tuve la fuerza reactiva necesaria para dejar que fuera la inercia (de la que Gumbrecht habla) la que permitiera que mi incomodidad ante los desafíos recientes actuara por obra propia. Me hubiera encantado, lo digo en serio, no tener que dar mi opinión sobre los retos, desafíos, problemas y críticas que merodean hoy en torno al tema de la educación a distancia. Y no hubiera querido, porque me muevo entre tres posturas que son, además de conflictivas entre ellas, motivos de conflicto interno. En pocas palabras, su acalorada lucha me impide adoptar una posición clara. Menciono, por tanto, estas tres posiciones.

La primera la expresa H. U. Gumbrecht mejor que yo: ofrecer resistencia al furor por reemplazar la educación presencial por la educación a distancia. Su posición, dicha fuera de contexto, parece ser 
herencia de un romanticismo rebelde, pero nostálgico, que no quiere dejarse arrastrar por la novedad, porque teme perder las certidumbres de un mundo conocido. En realidad, la tesis de Gumbrecht es mucho más compleja (Gumbrecht, 2005). Aunque, hay que decirlo, el libro del que tomé el epígrafe está sobrecargado de afectos. Es decir, está escrito con la intención de mostrar que las preguntas que lo inquietan, que lo mueven, que han propiciado un desarrollo intelectual vital, han sido formuladas siempre desde contextos presenciales, afectivos, donde los cuerpos se acompañan de espacios habitados: playas, ciudades, mesas de discusión, conversaciones largas, lazos afectivos, vínculos con alumnos, profesores y colegas.

Rostros y alimentos se entrecruzan en un libro que hace una especie de elogio de la proximidad, del contacto, aunque nunca renuncia a la necesidad de distancia que todo trabajo intelectual requiere. Distancia y presencia son los temas que trata de encarar para hablar del futuro de las humanidades. Uno de los pasados que Gumbrecht recupera es Humboldt, para quien la enseñanza académica debía caracterizarse por el "entusiasmo producido por el libre intercambio de profesores y estudiantes" concentrados en "problemas sin resolver".

Tomando este "deber ser" del mundo académico al que se adjudica la creación de la universidad moderna, Gumbrecht señala que sólo el entusiasmo producido por el libre intercambio puede ser estrategia para encarar esos problemas sin resolver; la presencia física estimula, ordena, coordina, adhiere. Por ello, sólo el conocimiento estable, acabado, indudable -si es que eso existepuede ser transmitido a distancia. Ahí no hay reformulación, crítica, movimiento ni desplazamiento, dice el autor, porque no hay problema complejo. Pero cuando aparece la complejidad, cuando el conocimiento no ha domesticado la realidad, las respuestas ante dichos problemas tendrán el estatuto de minieventos, es decir, asuntos que ocurren en un lugar y que son completamente impredecibles y, por lo tanto, "decisivos para el desarrollo futuro de la interacción entre profesor y estudiante". 
$\mathrm{Al}$ adherirme a Gumbrecht resulta claro que no me gusta pensar en la docencia como una práctica sin presencia, sin relación cara a cara, sin vínculo. Hasta aquí mi primera posición. Queda una pregunta: ¿La educación a distancia no puede, por motivo alguno, producir minieventos?

La siguiente posición que me gusta tomar es la de la distancia, la de la pregunta. Posición extraña, porque revela la aporía que esta noción produce: estar colocado y no querer estar en ningún lado. Posición de la universidad desde el siglo XVIII, al menos. Mirar desde la torre de marfil lo que le pasa al mundo. Derrida es ahora la puerta de entrada, con todas las paradojas que incluye su propuesta, al preguntar: ¿dónde se encuentran hoy el lugar comunitario y el vínculo social de un "campus" en la época ciberespacial del ordenador, del teletrabajo y de la world wide web? No entro al tema por incompetencia. Aclaro, sin embargo, que, de estar interesado en algo, es este el tema que más me inquieta: ¿qué pasa con nuestras formas de vinculación, de producción de lugares y espacios, de construcción de subjetividades, de fabricación de memorias y de producción de historia en la era de la desterritorialización de las nuevas tecnologías? Lo dejo, pero conservo el tema como uno de los que debemos seguir pensando en toda universidad.

La tercera posición, la más extraña de todas, después de las que ya he mencionado, es la de usuario. No soy, lo digo con franqueza, un usuario "competente" de la red, pero tampoco un "desentendido". Tengo abierto todo el día mi correo electrónico, establezco contacto con personas de distintos lugares del mundo (aunque pocos), sostengo vínculos amistosos mientras trabajo, avanzo en mi tesis de doctorado (que no es a distancia, pero casi) a través de Internet, leo el periódico, bajo artículos, he elaborado dos comunidades virtuales, hice un blog para estimular los vínculos en el trabajo de servicio social que coordiné y, para colmo (a pesar de mis inercias románticas y nostálgicas en contra de las nuevas estrategias didácticas), hice un curso de metodología de la investigación histórica que actualmente 
corre en una modalidad que me gustaría llamar "a distancia", pero con arraigo presencial. Lo que quiero decir es que, a pesar de tener en la cabeza algunas resistencias bajo la influencia de Gumbrecht, o preguntas y dudas bajo la apabullante presencia de Derrida, ya entré al futuro. Desde esta experiencia, quisiera presentar algunas reflexiones sobre las preguntas un tanto generales antes elaboradas; pero, también, que puedan servir a la discusión más local de cómo podemos incorporarnos a la educación a distancia en una universidad como la nuestra.

\section{La experiencia reciente}

Al igual que otros profesores de la Universidad del Claustro de Sor Juana (UCSJ), hace algunos meses participé en un curso de educación a distancia. Éste tenía como finalidad aprender la lógica de la plataforma que la Universidad Nacional Autónoma de México (UNAM) ponía a nuestro servicio para este fin. ${ }^{i}$ Mi entusiasmo no fue completamente el esperado. Gumbrecht y sus ideas me habían sugerido que la inercia silenciosa y la acción presente de seguir dando clases presenciales harían su labor y me ayudarían a salvarme de enfrentar estos nuevos desafíos didácticos. Pero el curso estaba armado y mi posición de usuario, que ya describí, no me permitía oponerme radicalmente a esta nueva experiencia. Las clases fueron agradables, eficientes, ordenadas, con todos los problemas y virtudes que un curso presencial tiene: los profesores de la UCSJ nos volvimos alumnos. No relato toda esa experiencia porque nunca acabaría. Sin embargo, me parece que sería muy útil pensar en colectivo cómo nos comportamos nosotros como alumnos para comprender mejor lo que nuestros alumnos hacen y dejan de hacer hoy en nuestras clases. No fuimos muy diferentes a ellos.

Terminé el curso a tiempo. Nunca lo hubiera conseguido sin la invaluable ayuda de la coordinadora pedagógica, quien dio

i La Universidad del Claustro de Sor Juana es una pequeña universidad privada, con vocación pública y de perfil enteramente humanista. 
formato a lo informateable por mí y que añadió a mi trabajo varias horas del suyo. Terminé por una simple y sencilla razón: todo el material ya lo tenía elaborado. El cuaderno de trabajo que realicé en dos años de trabajo, y que fui poniendo a prueba en mis cursos presenciales, se volvió el curso a distancia que hoy existe. Como era un curso de apoyo a la presencialidad, no fue necesario desarrollar un amplio trabajo sobre las actividades de aprendizaje, pues éstas las haría fundamentalmente en el salón.

Los comentarios que recibí de los revisores fueron sugerentes: reducir la extensión de mis materiales, diversificar las actividades de aprendizaje, hacer que el alumno se convierta en un actor, es decir, hacerlo participar mucho más, usar más recursos para que los materiales fueran más atractivos: poner imágenes, fijar la atención, hacer participar al alumno constantemente. Me gustaron las observaciones. Imagino que leer el curso les llevó unas cuantas horas más de trabajo. Sus sugerencias generarán, en caso de seguirlas, muchas horas más de tiempo invertido. Y ello, lo digo también tratando de ser sincero, sin disminuir la extensión de mis materiales y sin preocuparme por hacer las cosas "más atractivas". Desde luego es Gumbrecht el que ha seguido acechando: los problemas son problemas y no hay que dosificarlos, masticarlos, reducirlos para que los alumnos aprendan más fácil.

Ahora que estoy casi por terminar de impartir el curso este semestre, me gustaría anotar algunos de los resultados:

1. El curso empezó bien: a distancia con poco apoyo de lo presencial. Al mes, más o menos, la distancia distanció a la mitad -al menosde los alumnos. No se acostumbraron. Por ello, se hizo menos a distancia y más presencial. Al final, casi al final, es prácticamente presencial, sólo acuden a los materiales, que, además, tengo que dar nuevamente en clase. ¿Es un desastre?

2. Primera respuesta: no. La mitad, un poco más, le ha sacado mucho provecho. Se metieron mejor en los temas, es decir, con mayor profundidad, establecieron contacto entre ellos a través de los foros; logramos -entre esa mitad y yo- establecer formas 
de vínculo escrito que sólo con los trabajos "convencionales" no se puede dar. Pero, es cierto, mucho de ello me gustó porque después les veía la cara y sabía más de ellos, porque en clase recuperaba sus preguntas y recuperábamos los diálogos y porque, cuando entraba a la plataforma, ya tenía incorporadas sus voces, gestos, modulaciones y tonos.

3. Segunda respuesta al desastre: sí. Porque la otra mitad, la pequeña (si esas divisiones las permiten los cálculos matemáticos) se desvinculó del curso. Dejó de existir no sólo en la plataforma, sino también en las clases. Desapareció.

Si estas tres cosas ocurrieron tal y como se las cuento quisiera señalar algunas conclusiones, unas que indican a lo posible y otras a lo dramático. Todo ello, dejando que las ideas fluyan sin mucho control.

1. Para que esto funcione hay que dedicar tiempo. Mucho. Los cursos en línea tardan bastante en cuajar. No sólo porque exponer un material se vuelve un riesgo diferente al de la clase: las cosas quedan escritas y ello siempre hace más dubitativa nuestra exposición. También, porque pensar correctamente las actividades es un asunto que no sabemos bien cómo realizar. No tenemos ni experiencia ni conocimientos al respecto.

2. La afectividad y el vínculo se pueden reforzar, pero no pueden surgir sólo de la distancia. A mí, por lo menos, me falta la presencia.

3. Explorar y explotar esta modalidad a medias, a distancia, pero con arraigo presencial, puede fortalecer nuestro trabajo en muchos sentidos:

a) A los profesores nos obliga a presentar mejor la información, a problematizar los temas, a pensar y a escribir.

b) A los alumnos les permite contar con materiales para trabajar y pensar, buscar más materiales, presentar su postura de manera horizontal frente al maestro, introducir dudas, compartir reflexiones con los demás alumnos, tomar una posición activa en su proceso de aprendizaje. 
c) Permite ampliar los vínculos entre alumnos y profesores, al mostrarnos cómo cada uno de los presentes-ausentes enfrenta la escritura, la usa para comunicar y para pensar.

d) Permite jugar con la ficción del lugar virtual para repensar la realidad del lugar territorial y del lugar de la universidad en la sociedad.

4. La conclusión grave, y quizás expuesta de manera apresurada, es más bien una pregunta: el hecho de dejar a la mitad de los estudiantes invisibles ante lo presencial y a la otra mitad mucho más presente, ¿sirve como metáfora de lo que producen las nuevas tecnologías en nuestra sociedad contemporánea? ¿No corremos el riesgo de acrecentar o producir olvidos, de fomentar la desaparición de algunos al fortalecer la existencia de otros? ¿Cómo hacer para no invisibilizarlos sin invisibilizarnos por quedarnos fuera del futuro? ¿No será este el reto (si la palabra no suena demasiado gastada) de nuestras reflexiones al interior de una universidad? Si entramos como los alumnos responsables que entraron, ¿a quién dejamos fuera? ¿Qué podemos hacer con ellos? Si no entramos, ¿de qué nos perdemos?

Espero haber provocado, aunque sea un poco, aunque sea en alguien, el entusiasmo para seguir pensando juntos, aquí, en un lugar común, cara a cara, sobre estos temas.

\section{Referencias bibliográficas}

Gumbrecht, Hans Ulrich. (2005) Producción de presencia. Lo que el significado no puede transmitir. México: UIA.

Recibido: 9 de mayo de 2006

Aceptado: 7 de junio de 2006 